\title{
Bemerkung zu der Abhandlung von Fileti und Ponzio „Umwandlung der Ketone in $\alpha$-Diketone"; von
}

\section{Claisen.}

Das letzte Heft dieses Journals ${ }^{1}$ ) bringt eine interessante Arbeit von Fileti und Ponzio, worin gezeigt wird, dass Ketone von der Formel $\mathrm{CH}_{3}-\mathrm{CO}-\mathrm{CH}_{2}-\mathrm{R}$ durch Salpetersäure, bez. salpetrige Säure in $\alpha$-Diketone, $\mathrm{CH}_{3}-\mathrm{CO}-\mathrm{CO}-\mathrm{R}$, verwandelt werden. Fileti und Ponzio schliessen daraus ${ }^{2}$, dass die Isonitrosoketone, welche Manasse und $i \operatorname{ch}^{3}$ ) aus den Ketonen $\mathrm{CH}_{3}-\mathrm{CO}-\mathrm{CH}_{2}-\mathrm{R}$ vermittelst Amylnitrit dargestellt haben, die Formel $\mathrm{CH}_{3}-\mathrm{CO}-\mathrm{C}(\mathrm{NOH})-\mathrm{R}$ und nicht die früher von uns befürwortete Formel $\mathrm{CH}(\mathrm{NOH})-\mathrm{CO}-\mathrm{CH}_{2}-\mathrm{R}$ besitzen.

Die Richtigkeit dieses aus sorgfältigen Versuchen gezogenen Schlusses erkenne ich ohne Weiteres an; Einspruch muss ich aber dagegen erheben, dass die genannten Autoren meine frühere Ansicht als eine definitive hinstellen und von einer bestimmten Regel sprechen, welche ich hinsichtlich der grösseren Reactionsfähigkeit der Methylgruppe in den Ketonen ausgesprochen haben soll. In der ersten Mittheilung ist nur gesagt, dass die ron Manasse und mir dargestellten Isonitrosoketone wahrscheinlich die ihnen beigelegte Constitution besitzen. Noch skeptischer habe ich mich später, vor anderthalb Jahren, über die Sache geäussert ${ }^{4}$ ): „Der Verlauf der Condensationen der Säureäther mit Ketonen von der allgemeinen Formel $\mathrm{CH}_{3}-\mathrm{CO}-\mathrm{CH}_{2}-\mathrm{R}$ bedarf in diesem Punkte" - es handelt sich um den Ort, wo das Säureradical eintritt „einer nochmaligen eingehenden Untersuchung; ebenso muss von den aus solchen Ketonen mittelst salpetriger Säure oder Amylnitrit dargestellten Isonitrosoketonen noch genauer festgestellt werden, ob sie die

1) Dies. Journ. [2] 51, 498.

2) Wie früher schon Gabriel u. Posner, Ber. 27, 1040.

3) Ber. 22, 526.

4) Ann. Chem. 278, 172; man vergl, auch die spätere Bemerkung in den Ber. 27. 1354. 
Claisen: Bemerk. z. d.Abh. von Fileti u. Ponzio etc. 77 Formel CH(NOH)-CO- $\mathrm{CH}_{2}-\mathrm{R}$ oder $\mathrm{CH}_{3}-\mathrm{CO}-\mathrm{C}(\mathrm{NOH})-\mathrm{R}$ besitzen."

Meine frühere Ansicht stützte sich hauptsächlich auf den von Ehrhardt und mir ${ }^{1}$ ) erbrachten Nachweis, dass die $\mathrm{Ke}$ tone von der mehrfach erwähnten Constitution mit Essigäther Diketone

$$
\left(\mathrm{CH}_{3}-\mathrm{CO}\right) \mathrm{CH}_{2}-\mathrm{CO}-\mathrm{CH}_{2}-\mathrm{R}
$$

und nicht die isomeren Verbindungen<smiles>[R]C(C(C)=O)C(=O)OC</smiles>

liefern. Da die Sache theoretisch nicht ganz unwichtig ist, habe ich diese Untersuchung wiederholt und das frühere Resultat vollkommen bestätigt gefunden. Amylnitrit und Essigäther verhalten sich also gegen Ketone $\mathrm{CH}_{3}-\mathrm{CO}-\mathrm{CH}_{2}-\mathrm{R}$ sonderbarer Weise ganz verschieden; der Salpetrigsäurerest tritt in die Methylengruppe, der Acetylrest in die Methylgruppe des betreffenden Ketons ein. Zweifelhaft bleibt die Wirkungsweise des Ameisenäthers; ich hoffe später auf diese Frage zurückzukommen und entscheiden zu können, ob die durch ihn erzeugten Oxymethylenketone der Formel $\mathrm{CH}(\mathrm{CH} . \mathrm{OH})-\mathrm{CO}-\mathrm{CH}_{2}-\mathrm{R}$ oder $\mathrm{CH}_{3}-\mathrm{CO}-\mathrm{O}(\mathrm{CH} . \mathrm{OH})-\mathrm{R}$ entsprechen; in den bisherigen Mittheilungen hatte ich der ersteren Formulirung den Vorzug gegeben.

1) Ber. 22, 1016 . 